\title{
Pushing the Margins of Responsibility: Lessons from Parks' Somnambulistic Killing
}

\author{
Filippo Santoni de Sio • Ezio Di Nucci
}

Received: 3 May 2016 / Accepted: 16 February 2017 / Published online: 22 March 2017

(C) The Author(s) 2017. This article is published with open access at Springerlink.com

\begin{abstract}
David Shoemaker has claimed that a binary approach to moral responsibility leaves out something important, namely instances of marginal agency, cases where agents seem to be eligible for some responsibility responses but not others. In this paper we endorse and extend Shoemaker's approach by presenting and discussing one more case of marginal agency not yet covered by Shoemaker or in the other literature on moral responsibility. Our case is that of Kenneth Parks, a Canadian man who drove a long way to his mother-inlaw's and killed her in a state of somnambulism. We support our claim about Parks' marginal responsibility in three steps: we first deny that Parks acts involuntarily as traditionally claimed in the legal literature; we then propose to extend Shoemaker's analysis of marginal responsibility based on quality of will so as to include two other dimensions: the moral status of the agent and the actual causal effects of their actions; finally, we distinguish Parks' marginal responsibility from four other existing concepts: "tracing" (drunken cases), diminished responsibility (minor mental disorders), causal responsibility (Williams' unlucky lorry driver), and
\end{abstract}

F. Santoni de Sio $(\bowtie)$

Section Ethics/Philosophy of Technology, Delft University of Technology, Jaffalaan 5, 2628BX Delft, The Netherlands e-mail: f.santonidesio@tudelft.nl

E. Di Nucci

University of Copenhagen, Øster Farimagsgade 5,

DK-1014 Copenhagen, Denmark

e-mail: ezio@sund.ku.dk moral disapproval without responsibility (bad actions by small children, animals, or machines).

Keywords Consciousness and moral responsibility . Marginal agency $\cdot$ Marginal responsibility $\cdot$ Reactive attitudes $\cdot$ Strawsonian theory of responsibility $\cdot$ David Shoemaker

\section{Introduction}

When it comes to moral responsibility, we do not believe in a simple dichotomy. A binary distinction between being morally responsible and not being morally responsible leaves out something important. In Responsibility from the Margins [1] David Shoemaker has argued against a binary approach by claiming that this leaves out instances of what he calls "marginal agency", cases where agents seem to be "eligible for some responsibility responses but not others" (4). In this paper we endorse and extend Shoemaker's approach by presenting and discussing one more case of marginal agency not yet covered by Shoemaker or in the other literature on moral responsibility. Our case is that of Kenneth Parks, a Canadian man who was acquitted for the murder of his mother-in-law in 1987 on the grounds that he was sleepwalking during the act. Whereas we agree with Parks' legal acquittal, in this paper we address the issue of Parks' moral responsibility. In Parks' case it seems difficult to say that he is morally responsible for killing his mother in law; but it seems also unsatisfactory to have to just equate his story with a random accident, for 
which no normative evaluation of the agent would be appropriate.

We endorse a Strawsonian approach to responsibility insofar as we center our responsibility analysis on the (appropriate) emotional responses or "reactive attitudes" towards human agents. However, we also endorse Shoemaker's criticism of Strawson's idea of "quality of will" of the agent as being the sole explanatory or justificatory element for reactive attitudes. In fact, we push Shoemaker's critique even further. Shoemaker advocates for a broader, pluralistic, quality of will approach, one that can help making sense of some reactive attitudes towards a set of agents affected by mental conditions impairing some of their general capacities for moral agency: depression, psychopathy, autism. We propose to add to the analysis of marginal responsibility two other dimensions: the moral status of the agent and the actual causal effects of their actions. By doing so, we will be able to push the margins of responsibility a bit further so as to cover a case like Parks, a mentally sound person killing while asleep.

Our main claim is that Parks, while both falling short of fully satisfying what we see as the three conditions for moral responsibility - status, voluntary action, causation and falling short of manifesting any bad will in any of the senses mapped by Shoemaker may be still seen as responsible in some way for his behavior. Parks, we argue, is a full moral agent whose clouded consciousness is both temporary and partial (status condition); his actions are not involuntary and goal-directed (voluntary action condition); the death of Parks' mother-in-law is nondeviantly causally dependent on his actions (causation condition). That's why, we argue, failing to be open to standard moral reactions like blame and condemnation, Parks can still be legitimately open to some resentment, at least from those who have suffered because of his actions.

Indeed, literature on moral responsibility has covered various hard cases which may be seen in some respect as similar to Parks: indirect moral responsibility (aka "tracing", like in classic drunken cases), diminished responsibility (Shoemaker's agents affected by mental disorders), sheer causal responsibility (Williams' unlucky lorry driver), and mere moral disapproval without responsibility (bad actions by small children, animals, and smart machines). We claim that Parks' case is relevantly different from these, and we devote the last section of this paper (Beyond Tracing, Diminished Responsibility, Moral Disapproval without Moral Responsibility, and Causal Responsibility Section) to map these differences.
Before that, in Involuntariness and Parks Acts Sections we challenge the traditional legal approach [2-4], which describes agents like Parks as acting involuntarily; in Parks' Moral Responsibility Section, we present and endorse the claim shared by traditional theories of moral responsibility according to which Parks is not paradigmatically blameworthy for his actions; we move beyond this traditional approach by endorsing Shoemaker's idea of marginal responsibility; and we propose to extend the analysis of marginal responsibility so as to include moral status and causation as two of its dimensions; in this way we set the stage for our claim about Parks' marginal responsibility. In Parks' Marginal Moral Responsibility Section, we then present and defend our case about Parks' marginal responsibility.

\section{Involuntariness}

In the early hours of May 23rd 1987 Parks rose from the couch on which he had fallen asleep, put on his shoes and jacket, walked to his car and drove $23 \mathrm{~km}$ to the home of his parents-in-law; he entered their house, strangled his father-in-law into unconsciousness and stabbed his mother in law to death. He then drove to a nearby police station where, in a state of great confusion, he said that he thought he had probably killed someone. ${ }^{1}$

Parks was acquitted for the killing of his mother-inlaw and the serious injury to his father-in-law, as it was proven that even if the killing and the injury had been done by him, he did them in a state of somnambulism, and so he qualifies for the defence of "non-insane automatism" [5]. In the legal literature, the standard interpretation of this kind of acquittal is that people like Parks are not liable as their behaviour cannot be seen as voluntary action [6]. Here is Herbert L.A. Hart ([2]: 105): "In the unconscious cases ... the movements that we call involuntary are not part of any action the agent takes himself to be doing"; and here is Michael Moore [3]: "without consciousness ... sub-personal agencies do not represent our willing or our action". That automatism is seen in the law as amounting to involuntariness

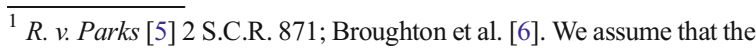
reconstruction of the facts done in court is accurate and Parks was really in a state of somnambulism when he did what he did. Moreover, we rely on current scientific accounts of somnambulistic action as they are presented, for example, in Ebrahim and Fenwick [7] and Morrison et al. [8].
} 
of action and not only to a lack of specific intention in a voluntary action ${ }^{2}$ is relevant for our purposes; in fact, by denying the voluntariness of action, legal automatism works as a complete defence for any kind of legal responsibility; not only for crimes for which intention is required (e.g. theft or murder), but also for wrongs for which specific intention is not required, i.e. negligence, strict liability or tort liability [2].

In this and the following section we challenge this view by arguing that Parks' somnambulistic behaviour should not be considered as involuntary action and that (at least part of) his behaviour during his somnambulism episode should count as genuine agency. These two claims are related to each other but we will defend them in turn starting from the former.

A first possible way of arguing for Parks' involuntariness is to appeal to the unconscious or unaware nature of his behaviours. Here one could just stipulate that voluntary action is necessarily conscious or aware and argue that since Parks' behaviours during his somnambulism episode are unconscious or unaware, then Parks' behaviours are, by definition, involuntary. In order to make this claim plausible one will have to preliminarily show that Parks' behaviour during the somnambulism episode is indeed unconscious or unaware - and that is a complicated matter which partly depends on empirical considerations. Secondly, one will have to also show - again preliminarily - that consciousness or awareness is indeed necessary for voluntariness.

As for the question of Parks' consciousness, states of somnambulism are uncontroversially states which are less than fully conscious - being awake is, after all, one paradigmatic way of being conscious. However, sleepwalkers like Parks are also clearly not fully unconscious - they have open eyes and are sensitive to some environmental stimuli [6]. As for Parks' consciousness being or not sufficient for voluntariness, an important point in this respect is that many actions are carried out in a less than fully conscious way. Indeed, we often act habitually or automatically without previous reflection on what we are going to do and also without attention to our performances while we are acting ${ }^{3}$ : think of walking up a flight of stairs; typing your pin number; shifting gear while driving home; going through your morning

\footnotetext{
2 More on the relation between voluntariness and intention below in this section, where Davidson's theory is discussed.

${ }^{3}$ See Wigley [9], Di Nucci [10-12]
}

routine; carrying out complicated skilled performances such as those involved in sport or music. In these and related cases actions appear to be less than fully conscious: it's not just that we don't need previous deliberation or conscious attention to the performance; often conscious involvement would be counterproductive to the successful completion of the task. ${ }^{4}$ Still, we usually consider these to be fully voluntary actions.

It is important to point out that at least some of the tasks that Parks successfully completes during his episode of somnambulism are automatic and habitual in the relevant sense: Parks amazingly drives more than $20 \mathrm{~km}$ to get to his in-laws, and such a long drive involves several learned skilled performances that Parks has acquired through years of practice. Admittedly, Parks' actions are different from those in the examples described above [9]. Following a useful distinction proposed by Levy [15], ${ }^{5}$ it can be said that habitual and automatic behaviour while awake are cases of 'local automatism' whereas Parks' somnambulistic actions are an example of 'global automatism'. However, as Levy himself admits, the mechanisms underlying local and global automatism may be the same - Levy calls these mechanisms action scripts - so that it is at least not obvious that global automatism is incompatible with the performance of voluntary actions. ${ }^{6}$

A second way of defending the involuntariness of Parks' actions would be to appeal to a Davidsonian account of action. According to Davidson [17], some movement is an action only if it intentional under at least one true description. If Parks' movements during his episode of somnambulism turned out to be intentional under no description, then none of his movements would turn out to be actions in Davidsonian terms. Is this the case? Intentional action, according to Davidson, means action caused by the agent's relevant beliefs and desires. Again, there is no reason to assume that Parks does not desire to open the door, drive his car, etc., or that these actions are not caused by relevant beliefs of his.

\footnotetext{
${ }^{4}$ There is plenty of relevant empirical data here - for example Beilock's experiments with expert golfers - see [13, 14].

${ }^{5}$ See also [16].

${ }^{6}$ Indeed, Levy only argues that global automatism is incompatible with responsibility, without arguing that it is incompatible with agency. We discuss issues of responsibility in Parks' Moral Responsibility, Parks' Marginal Moral Responsibility and Beyond Tracing, Diminished Responsibility, Moral Disapproval without Moral Responsibility, and Causal Responsibility Sections below.
} 
One could try to describe Parks' individual actions as unintentional in the sense of mistaken, as in caused by ignorance of relevant details or false beliefs. In Davidson's classic case of unintentional action [17], an agent boards a plane headed to London, Ontario with the intention to board a plane headed to London, England.

However, some of Parks' actions are clearly guided by his true beliefs and knowledge, e.g. he takes what he knows to be his car as he correctly believes that it is a good way to reach what he knows to be his in-laws' house, and he gets there because he knows the way. ${ }^{7}$ Secondly - and more importantly - even if one were to concede that Parks' actions were unintentional in this sense, this would not make them involuntary. Davidson's unfortunate passenger is intentionally boarding a plane, even though by being ignorant or mistaken about its destination he is not intentionally boarding a plane headed to London, Ontario. Note here that it is the very same description which is unintentional that is not involuntary: Davidson's unfortunate passenger unintentionally but voluntarily boards a plane headed to London, Ontario. Something similar may be true of Parks' actions. ${ }^{8}$

Before concluding this section, we would like to anticipate a further possible objection. It may be thought that what we have said so far may apply to some but not all of what Parks does during his somnambulism episode. Here is Levy again: "Violence in these cases may be caused when the overlearned script is interrupted, with the interruption interpreted by the unconscious agent as a threat" ([15]: 75; see also [18]). So that, in Levy's language, while the driving, say, goes according to the script, the killing is only the result of the sudden interruption of that very script. We do not want to dispute this psychological explanation of sleepwalking violence and killing, or to deny that there are differences between, say, Parks' driving and Parks' killing.

However, first, even if Parks' stabbing of his motherin-law was indeed the result of a sudden interruption of an overlearned routine (and in this respect different from everything else that Parks does during his episode), that would still not make it comparable to a simple reflex, because of the skilful and coordinated response to the environment involved. Even Levy admits that Parks' "action of stabbing his mother in law... was certainly caused by content bearing mental states. It was not a

\footnotetext{
${ }^{7}$ More on this in Parks Acts section below.

${ }^{8}$ Again, here see [9].
}

mere reflex; it employed a tool in a manner appropriate to that tool... Parks utilizes a knife in a knife-appropriate manner, thereby responding to the overlearned affordances" ([15]:66). ${ }^{9}$ Moreover, for the purposes of our argument the actual character of Parks' stabbing is not crucial: firstly, because whether or not Parks' routine was interrupted in the above way, that would not change the nature of what he does before the interruption; and secondly and most importantly, because it is possible to imagine alternative cases of sleepwalking where agents do morally relevant things which are not the consequence of an interruption.

It is at least not obvious, we have argued in this section, that Parks acts involuntarily. Now we argue that this is because what Parks does during his episode of somnambulism should count as genuine agency.

\section{Parks Acts}

Our basic claim is that it is an unhelpful simplification of human agency to equate Parks' complicated performances during his episode of somnambulism with paradigmatic involuntary actions like reflex movements or epileptic fits. ${ }^{10}$ We argue that at least some of Parks' performances during his somnambulism episode are genuine actions, by showing in which relevant ways what Parks does is different from the mere movements which sometimes just happen to us without being done by us: reflexes; epileptic fits; being pushed over.

There are two separate ways in which what Parks does shares many important features with paradigmatic human actions: on the one hand in terms of the performance itself and on the other hand in terms of their relation with the individual agent who is the author of the performance. In terms of Parks' performance, this has many features in common with paradigmatic actions:

a) Parks' performance is goal-directed: Parks presumably gets up, opens his front door and that of his garage, goes to his car, opens it, turns it on, drives it off onto the road and follows a more than $20 \mathrm{~km}$ long route to the house of his in-laws, then steps out of the car and into the house; in turn, these

\footnotetext{
${ }^{9}$ Levy in the same passage also writes: "However, like the actions of the alien hand, the behaviour is driven by low level motor representations, not by the personal level beliefs of the agent" ([15]:66).

${ }^{10}$ A position endorsed by Moore [3], Schopp [4], and criticised by Williams [19] and [20].
} 
performances require many complicated subordinated activities in order to be successfully carried out. This complicated structure of different levels of goal-directed behaviours cannot be compared to random goalless movements that we sometimes perform both when asleep and when awake;

b) Parks' performance requires a high degree of coordination: anybody who has gone through the challenging and time-consuming practice of learning how to drive a car can testify to the amount of coordination that only that particular part of Parks' performance requires; these are not basic or simple acts, like the proverbial (at least in philosophy) raising of one's arm - these are activities which a statistically relevant percentage of the human population never masters; this level of coordination shows that the performances in question have nothing to do with luck or randomness;

c) Parks' performance is responsive to the environment: as Parks drove more than $20 \mathrm{~km}$, we must assume that he must have overtaken other cars; he must have in turn been overtaken; he will have likely reacted to and avoided objects and other obstacles both on his drive and on his way to the car and from the car; we also know, for example, that Parks must have driven through at least four different sets of traffic lights on his way to his inlaws. Also think of the non-trivial problem solving involved in what Parks achieved: already getting into the house of his parents-in-law constituted a complex problem that Parks had to solve and did solve while sleepwalking; this shows a significant degree of flexibility and responsiveness to a changing environment;

d) Exercise of individual ability and skills: see above; but also suppose that Parks had been a soldier or a butcher who had taken his gun/knife with him or had used the gun/knife he found in his in-laws' house. The point is that the abilities and skills required in such a case aren't just general but they rather have to do with the particular training and biography of the individual agent so that we can meaningfully attribute the performance to a particular skilled and trained agent.

Those are all features which Parks' performance during his somnambulism episode shares with paradigmatic cases of action; so that if we said that Parks just moves his body but does not perform genuine actions during his episode of somnambulism, we wouldn't be able to explain any of the important features above.

So far we have focused on the nature and properties of Parks' performance - but we should also emphasize the important links between Parks' performances and Parks himself as an individual agent. Parks also deploys individual abilities and knowledge such as his ability to drive along a route that he knows well, for example. Not everybody could have done what Parks did - no matter if asleep or awake: this distinguishes Parks' complicated performances during his sleepwalking episode from more basic movements while sleepwalking (or even while just sleeping or being awake) that just any able body could perform.

Summing up, there are at least two different ways in which what Parks does can and should be distinguished from mere bodily movements: on the one hand, Parks' movements are goal directed, coordinated, responsive to the environment, and also the expression of individual abilities, skills, and knowledge - in this respect Parks' movements share those agential features with paradigmatic actions. On the other hand, there are features of the situation which enable us to identify Parks as the agent of those performances: for example Parks' individual history and Parks' individual capacities and knowledge.

\section{Parks' Moral Responsibility}

Parks should not be held criminally liable, and he is not a good candidate for what we may call paradigmatic moral responsibility either. In this sense, we do not disagree either with mainstream legal literature or with mainstream non-Strawsonian theories of moral responsibility (e.g. Fischer-Ravizza [21], Levy [15], Frankfurt [22]). Our concern is not that these theories deliver the wrong result about Parks' moral blameworthiness; it is rather that, binary as these theories are, once they have denied, respectively, legal culpability and moral blamewothiness, there is nothing else that they can say about the moral appropriateness of reactive attitudes towards Parks.

That is where Strawsonian theories may have an advantage: they are able to allow for reactive attitudes towards Parks; the problem with these approaches is that, on the emotivist version which just reduces moral responsibility to reactive attitudes, Parks will implausibly turn out to be paradigmatically morally responsible - so that on these theories, for instance, his wife leaving 
him as a reaction to his deeds would just amount to Parks' moral responsibility.

A more fruitful approach, in this respect, is represented by those Strawsonians [1, 23, 24] who, following up on Strawson's original statement on the relevance of the agent's will in triggering moral reactions, distinguish between appropriate and inappropriate reactive attitudes and insist that moral responsibility amounts to appropriate moral reactions: other reactions, however psychologically understandable, are not morally defensible. In particular, in his Responsibility from the Margins [1], Shoemaker has proposed to expand the quality of will approach so as to make sense of marginal agency, a set of instances of agents which seem to be "eligible for some responsibility responses but not others".

Shoemaker thinks that one's will can be bad (or good) in different ways, and thus we need a more sophisticated and fine-grained analysis of what a bad (or good) will is and which responses are appropriate to which kind of badness (goodness). He calls this a pluralistic approach to quality of will. According to Shoemaker when we react to someone's bad will we may be reacting to three different things: their bad character, their wrong judgement, and their poor regard. An important consequence of this is the following: as some agents may and in fact do lack the capacity or competence to express one or more of these qualities of will (but not others) - they may be "exempted" from some legitimate reactive attitudes but not from all of them. For instance, according to Shoemaker, it is not fair to negatively react to a psychopath's behavior because of the wrong normative judgements it is based upon, insofar as psychopaths allegedly lack the relevant capacity for moral judgement; however, it is fair to negatively react to the cruelty of a psychopath behavior, insofar as this is evidence of a bad character. Based on his tripartite model of quality of will, Shoemaker presents and discusses a series of mental conditions which make agents able to express not full but only marginal moral agency, and are therefore open to only some but not the full range of reactive attitudes. These conditions include depression, scrupulosity, psychopathy, autism, mild intellectual disabilities, deprivation and dementia. Whereas we endorse Shoemaker's project of mapping the varieties of marginal agency and marginal moral responsibility, we think that Shoemaker's map is not complete. In what follows we propose to consider Kenneth Park's somnambulistic killing as a new case of marginal agency, one for which one specific kind of moral reaction is appropriate. Whereas admittedly rare, the case highlights two important general respects in which Shoemaker's account may be integrated: accounting for cases where a generally competent moral agent finds himself acting under mental conditions that temporarily impair his intellectual and moral capacities (the importance of moral status); highlighting the importance of the causal effects of behavior in the world (some people but not others may legitimately respond to someone's behavior).

Shoemaker's focus is on quality of will: whenever an agent is unable to exercise any relevant moral capacity then they are exempted from any moral responsibility. That means that they are not appropriate recipients of any reactive attitude by anyone. We think this is an undesirable conclusion. In our view blame, condemnation and resentment are typically appropriate when the following conditions are met ${ }^{11}$ :

- (STATUS) at the time of action the agent is a full member of the moral community, i.e. she is not a small child, or seriously mentally disabled;

- (VOLUNTARY ACTION) the agent's behaviour is not involuntary, in the sense of being attributable to him as something she did, not something that happened to her (a reflex, a fit, etc.);

- (CAUSATION) the agent's behaviour has the right causal connection with a bad outcome (causation requirement);

Parks is not paradigmatically morally responsible because whereas he meets the causation condition he falls short of fully satisfying the status and voluntary action conditions. In fact, as for the voluntariness requirement, his condition of clouded consciousness makes his actions not fully attributable to him; for instance, he is not sensitive and responsive to many relevant stimuli that may modulate or inhibit his action ${ }^{12}$; as for the status requirement (3) though Parks is not a child or a mentally disabled person his rational capacities i.e. mental, linguistic, social - during the somnambulism episode are dramatically limited, in a similar way as that

\footnotetext{
$\overline{11}$ We follow and adapt here Bernard Williams' [25] four elements list: cause, state, intention, response. Our list also reflects some basic legal requirement for criminal responsibility present in the majority of legal criminal systems, namely: the causation requirement, the voluntary act requirement, the mental capacity requirement (not being a child or legally insane).

${ }^{12}$ Schopp [4]; Levy and Bayne [16].
} 
which make small children and some mentally disabled generally non-responsible for their actions. For instance, Parks is not responsive to a wide set of features of the environment, cannot arguably attribute meaning and value to any states of affairs, cannot set complex goals and structure his behaviour consistently towards the pursuit of those goals, is not responsive to (moral) reasons against the pursuit of these goals, etc. Moreover, he doesn't seem to manifest any bad quality of will in any of the senses mapped by Shoemaker.

The status requirement is thus wider than the voluntariness requirement as the general reduction of mental capacities affects the moral status that an agent deserves in a community, whereas the involuntariness requirement concerns the psychological conditions of the subject in relation to the performance of one individual action or activity at a particular time. ${ }^{13}$

Given that Parks fails to fully satisfy two of the three basic requirements for moral responsibility, what we call the paradigmatic moral reactions - blame, indignation, condemnation, legal liability and punishment - do not seem to be suitable in his case. So far, we agree with most responsibility theorists. However, whereas these would stop here, we think there is more to say about Parks' responsibility.

\section{Parks' Marginal Moral Responsibility}

Imagine Parks was married to your sister; he would have then killed your mother. You will not only be extremely upset; you may resent him, because his behaviour has caused extreme suffering to you and yours for which there is no plausible justification. You may expect him to apologize, to make up, to show that he understands that he has caused you so much suffering through his actions. Imagine also that Parks, though deeply disappointed and sorry for what has happened, were to show that he does not understand why you would resent him, given that, so he thinks, what happened was just a very unfortunate circumstance for which no one (and anyway not him) carries any moral responsibility. We think Parks would be missing something important here.

\footnotetext{
${ }^{13}$ We thus here agree with Levy [15] and disagree with Wigley [9] that a state of automatism being global rather than local is relevant for the agent's moral responsibility as global automatism affects the agent's moral and legal status, whereas local automatism may not.
}

In the real story, Parks was left by his wife four years after his acquittal. We don't know the details of the story, nor do we want to make any speculations about it. ${ }^{14}$ However, let us just assume, for the sake of our argument, that Parks' wife ended up leaving him because she couldn't live with the fact that whereas she felt entitled to resent him, at least to some extent, for the death of her mother, he kept on behaving as if he had nothing to be resented for, and he insisted that in the end he was as much a victim of unfortunate circumstances as his wife was. Now, even without addressing the issue as to how much resentment would Parks' wife be entitled to, or as to what exact attitudes and actions should Parks take in order to make up for what he has done, we would agree that Parks' wife - like other victims in this story, and unlike complete strangers - is entitled to some (as opposed to no) resentment towards Park; and that Parks himself should feel and do something more than just being deeply sorry in order to try to make up for his catastrophic actions. So, while admitting that it would not be fair to hold Parks culpable for the killing in a paradigmatic way - e.g. call him a murderer, expect him to be jailed, allow the whole community to be resentful towards him - some actors in the story may legitimately have some negative moral reaction towards him, and he should not downplay his active and decisive role in the tragedy. This is the gist of our claim about Park's marginal moral responsibility.

In the rest of this section we provide arguments in support of our claim; in the next and final section we will highlight the difference between Parks' marginal responsibility and other existing concepts in the literature on moral responsibility.

In a nutshell, we argue that some particular moral reactions toward Parks from some actors, typically the victim's family, may be morally justified insofar as these may legitimately insist that: a) their suffering is the direct result of Parks' voluntary actions; and b) as a sane rational adult he is expected to understand that what he did has directly caused unjustified suffering to others. In the terms of the conditions for moral responsibility introduced above, we may say that not only Parks fully satisfies the causation requirement, as the death of his mother-in-law is unequivocally caused by his (voluntary) actions (Involuntariness and Parks Acts

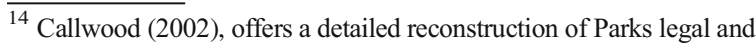
personal story, but her story stops at 1990, three years after the facts.
} 
Sections); but Parks also partly satisfies the status requirement.

One might be tempted to equate Parks' actions to the behaviour of a person affected by a serious mental disorder or a small child. Indeed, at the time of action Parks finds himself under mental conditions that make him - from a moral point of view - somehow similar to a small child or a seriously mentally disabled person (see section above). However, his somnambulistic condition is temporary, his rational and moral capacities only suspended, ${ }^{15}$ and his moral status as a responsible adult not generally affected. In fact, when Parks realizes what he has done, he is horrified and remorseful. And he consistently behaves as most decent adults would do, by reporting his deeds to the police. Parks is not a small child or a seriously mentally disabled person, even though he happens to find himself in a condition in which he cannot exercise his moral capacities. It is to establish this subtle equilibrium that Canadian law ${ }^{16}$ utilizes the concept of "non-insane automatism": Parks acts in a condition similar to that of a seriously mentally disordered person - that's why he is legally nonculpable for his actions - but he is not a mentally disordered person - that's why unlike insane agents he should not be treated as such, for instance by being limited in his other legal capacities or even by being eligible for compulsory mental treatment. ${ }^{17} \mathrm{We}$ argue that Parks' peculiar actions not only require a specific legal category but it also allows for a specific kind of moral reaction; namely, some limited amount of resentment from some particular agents directly affected by his actions.

Parks being a full moral agent before and after his episode makes an important moral difference. After the episode he can (and he actually did) realize the seriousness of what he has done. Moreover, his episode of somnambulism would not have happened had he not been a rational, sane and morally competent adult human agent before the episode. In fact, his episode was allegedly triggered by the emotional stress associated with his awareness of his problems and debts and with the prospect of talking about these with his family members. That Parks had been preoccupied by his debts and by how he illegally tried to cover them, and that he

\footnotetext{
${ }^{15}$ On the distinction between non-possession and suspension of a capacity see Kenny [26].

${ }^{16}$ English law has a similar construction.

${ }^{17}$ Broughton et al. [6], provided it is proven that similar episodes are extremely unlikely to occur again.
}

was nervous about having to tell his in-laws about his misdeeds on the next day is a basic - thought not sufficient - element in the explanation of some of Parks' acts. Finally, it is very likely that during his episode of somnambulism Parks 'decides' to go to his in-laws' as opposed to any other place precisely because of the complex network of desires and fears that he feels towards them; and, as already mentioned in the discussion on voluntariness, he manages to get there by consistently deploying a number of individual skills and knowledge acquired while awake (he can drive, he knows the way there, etc.).

Admittedly, the causal connections between Parks rational capacities and his behaviour are clearly anomalous, as are those between his beliefs and desires and his somnambulistic decisions and actions. But this is not the point. The point is that it doesn't seem correct to describe Parks either as a seriously deranged person performing totally unintelligible actions or as a Dr. Jekyll and Mr. Hyde story, that being a case of a complete (pathological) dissociation of personality in which different personas share a body and "successive selves" cannot arguably be called to respond for the behaviour of "previous selves" [27].

By insisting on the importance of Parks' general moral status for his responsibility we are endorsing here a point already made, among others, by Watson [28], Scanlon [24] and McKenna [23] in the literature on moral responsibility. ${ }^{18}$ The main idea is that attributions of (moral) responsibility are, in McKenna's words, calls for conversation. This explains why no reactive attitudes are morally appropriate towards agents that cannot properly master the moral language (small children, seriously deranged persons or animals and machines). However, committed to a quality of will reading of moral responsibility as they are, these theories can only make sense of paradigmatic moral reactions such as blame and condemnation. We have claimed that whereas blame and condemnation may be appropriate only towards actions that reveal some morally objectionable attitudes or have some other strong connection to the agent's moral dispositions, some marginal reaction may be appropriate to actions that though not representative of any negative attitudes are still attributable to a moral agent, as something he has

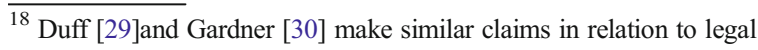
responsibility.
} 
done and he has to respond for. In this sense the closest approach to ours in the moral responsibility literature is George Sher's [31], insofar as he insists as we do that moral responsibility does not require either conscious awareness or an action tracking a morally reprehensible disposition of the agent; rather, it just requires that a morally reprehensible action is the effect of the agent's "collection of physical and psychological states whose elements interact to sustain his characteristic patterns of conscious and rational activity" (Sher [31]:124). ${ }^{19}$ Some version of Sher's theory might be more suitable to accept our claim about Parks' marginal responsibility than other theories of moral responsibility. Be that as it may, in its present version, Sher's is yet another theory of blame and condemnation, and it thus falls short of discussing the appropriateness of other forms of moral responsibility.

\section{Beyond Tracing, Diminished Responsibility, Moral Disapproval without Moral Responsibility, and Causal Responsibility}

Before concluding, we think it may be helpful to compare and distinguish our claim about Parks' marginal moral responsibility from four existing concepts in the literature about moral responsibility. We will claim that, on the one hand, marginal moral responsibility is different and arguably less serious qua moral responsibility than both "indirect moral responsibility" (aka "tracing"), and "diminished" or "reduced responsibility"; on the other hand, marginal moral responsibility is different and arguably more serious qua moral responsibility than both moral disapproval without moral responsibility and "causal responsibility" (see Table 1 below for a summary). By drawing these distinctions we aim to achieve three related goals: firstly, to give further support to our claim that traditional concepts do not cover Parks' case; secondly, to show that our claim about Parks marginal moral responsibility is a genuine original new philosophical reading of the story and not just a rationalization of a moral intuition implicitly triggered by a more traditional reading; thirdly, that our claim starts to fill a gap in the literature on moral responsibility.

\footnotetext{
${ }^{19}$ Cf. Smith and Tognazzini [32].
}

Tracing

Typically, people who wrong others while in a state of mental incapacitation - e.g. serious drunkenness - are thought to be culpable for their behaviour if their state of incapacitation is traceable to their previous culpable action, e.g. culpably getting drunk. People know or should know that by getting drunk they may end up wronging others, for instance by dangerous driving, so that when they do so they can be held morally responsible. In these cases, moral responsibility is traced back to the time in which agents were in possession of their rational and moral capacities; Levy [15] calls this responsibility deriving from a previous blameworthy actions "indirect moral responsibility". Unlike marginal moral responsibility, indirect moral responsibility is a full-fledged kind of responsibility that typically allows for a wide range of moral reactions including blame and condemnation. However, unlike the typical drunken wrongdoer, Parks could not anticipate that an episode of somnambulism with those consequences may have occurred to him on that night; therefore, even though his actions are somehow causally dependent on his previous culpable actions, they are not causally dependent in the right way, and he is thus not morally responsible according to a standard account in terms of tracing.

Indeed, our account of Parks' responsibility relies, among other things, on there being a connection between Parks' (wrong) behaviour while awake and his behaviour during his somnambulistic episode, but in a different way. We have pointed to some relevant connections between Parks' preoccupations at the time leading up to the somnambulism episode and what Parks does during his episode of somnambulism ${ }^{20}$; and we have also insisted that what Parks does during his episode of somnambulism would not be fully understandable without reference to his individual previous history. This kind of link is not such as to generate any tracing of moral responsibility. The reason why we have stressed the existence of these links between Parks' awake and somnambulistic life is just that this makes more difficult for his victims to see his actions either as totally random, i.e. non-attributable to any moral agent, or attributable to a totally separated moral agent, as it is somehow suggested in the case of agents affected by

\footnotetext{
${ }^{20}$ Parks' episode of somnambulism was most likely triggered among other things by the stress linked to his next day's very difficult meeting
} with his in laws. 


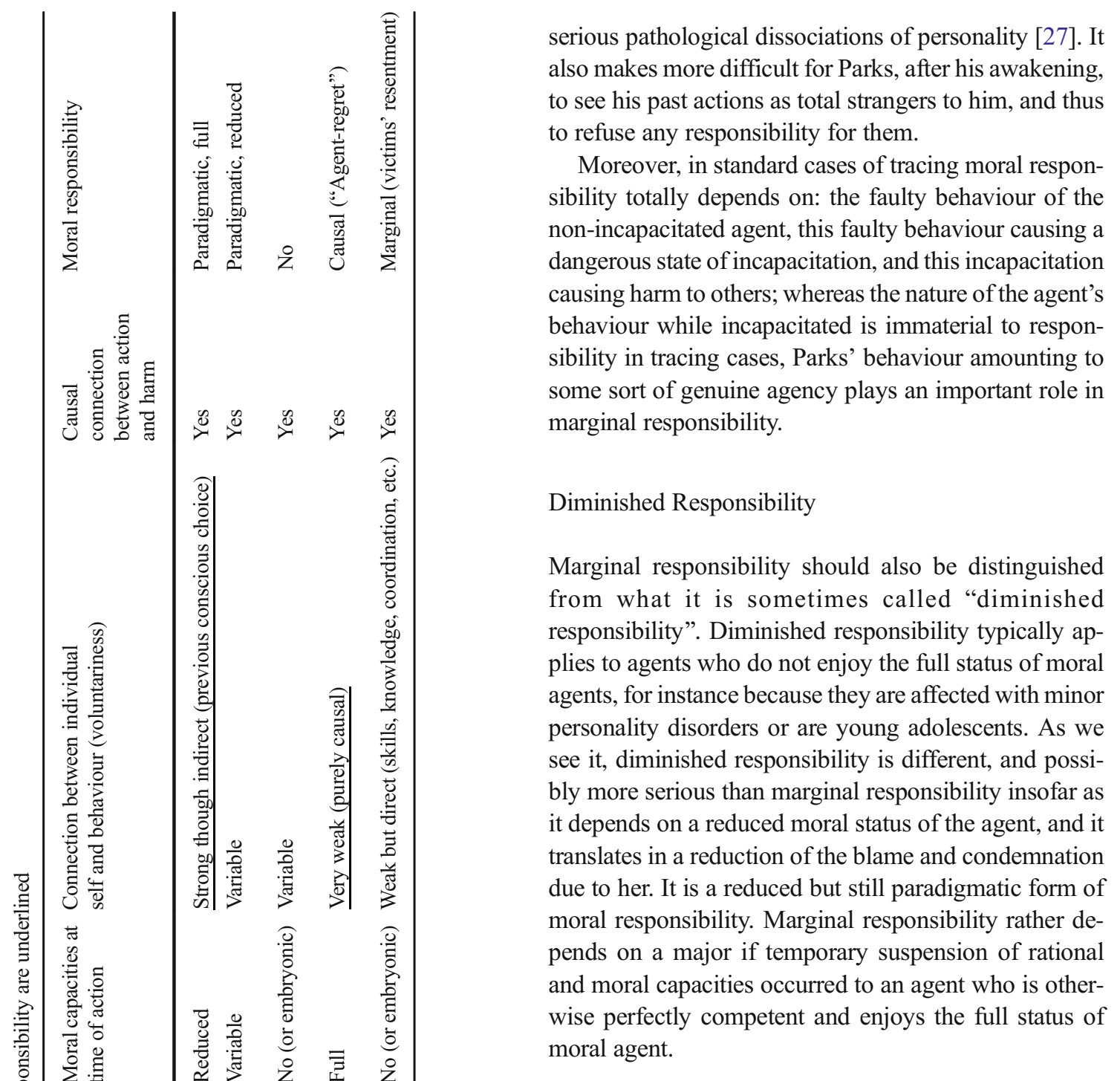

Moral Disapproval without Moral Responsibility

The fact that Parks enjoys, in general, the status of moral agent and his incapacitation is only temporary, makes his case also dramatically different, and arguably more serious than cases of agents who perform morally bad actions without enjoying that moral status. Think, for instance, of vicious dogs, small toddlers or intelligent machines carrying out bad actions or actions with relevant moral consequences. As they cannot be morally addressed or respond for those actions, these agents aren't the appropriate target of any moral reaction, though one may still legitimately express moral disapproval of their actions, and possibly have some emotional reaction to them. 


\section{Causal Responsibility}

Finally, it is important to note that the limited moral reactions associated with marginal moral responsibility, though less serious and wide-ranging than those involved in paradigmatic cases of moral responsibility, are still different and more serious than those legitimately arising in scenarios in which the agent's role is purely causal, and there isn't any relevant connection between the agent's self and his actions, such as those discussed in the moral luck literature - e.g. Bernard Williams' unlucky lorrydriver, Sofocle's Oedipus, etc. ${ }^{21}$ To highlight the difference between Parks and standard cases of causal responsibility, one can imagine the alternative story of Sam Parks, which is the same as Ken Parks except for three important elements: first, Sam Parks' somnambulism is triggered merely by the physical stress undergone in the previous days full of work and travelling in a sweltering climate; secondly, once in a state of somnambulism, Sam leaves his house on foot through an open door; thirdly, while wandering without any recognizable goal around his block, he happened to violently bump into an elderly passerby, who eventually falls to the ground, violently hits her head, and dies. ${ }^{22}$ We have argued that the victims' (relatives, say) resentment towards the real Ken Parks would be more appropriate than the victims' resentment towards the imaginary Sam Parks. Whereas Sam Parks' role in the killing is almost purely causal he accidentally kills a passerby he casually encountered while randomly wandering during an episode of somnambulism triggered by physical stress Ken Parks', for the reasons discussed above, is not. Sam's not Ken's story nicely fits with the idea of (tragic) purely causal responsibility. Ken Parks' story, though not less unfortunate and tragic, is so in a slightly different way, one that allows for a slightly but significantly different kind of moral reaction both on the side of the victims and on the side of the agent.

\footnotetext{
$\overline{{ }^{21} \text { Williams [33] }}$ and [25].

22 One may even add as a detail that the passer-by turns out to be Sam's mother in law who, for a pure chance, happened to be walking in his neighbourhood. This version of the story would more closely resemble Oedipus' and other cases of (tragic) purely causal responsibility as presented in Williams [33] and [25].
}

\section{Conclusion}

Our account makes sense of the inappropriateness of holding agents like Parks legally culpable or morally blameworthy without at the same time committing us to having to deny their moral responsibility altogether. Even though Parks' story is admittedly rather unusual, our point may have wider implications for the theory of responsibility. While acting in conditions that do not fully meet the standard criteria for blameworthiness, moral agents may be the fair recipients of some other appropriate moral reactions. Failing to be the fair recipients of blame and condemnation, human agents may still be marginally morally responsible for their actions. Shoemaker [1] has already mapped some cases of marginal moral responsibility. We have claimed that this map should be further integrated and we have started doing so. Future research will explore other cases of marginal moral responsibility.

Open Access This article is distributed under the terms of the Creative Commons Attribution 4.0 International License (http:// creativecommons.org/licenses/by/4.0/), which permits unrestricted use, distribution, and reproduction in any medium, provided you give appropriate credit to the original author(s) and the source, provide a link to the Creative Commons license, and indicate if changes were made.

\section{References}

1. Shoemaker, D. 2015. Responsibility from the margins. Oxford: Oxford University Press.

2. Hart, H.L.A. 2008. Punishment and responsibility: essays in the philosophy of law. Oxford: Oxford University Press.

3. Moore, Michael S. 2010. Act and crime: the philosophy of action and its implications for criminal law. New York: Oxford University Press.

4. Schopp, Robert F. 1991. Automatism, insanity, and the psychology of criminal responsibility: a philosophical inquiry. Cambridge: Cambridge University Press.

5. R v Parks. 1992. 2 S.C.R. 871. https://scc-csc.lexum. com/scc-csc/scc-csc/en/item/907/index.do.

6. Broughton, R., R. Billings, R. Cartwright, D. Doucette, J. Edmeads, M. Edwardh, F. Ervin, B. Orchard, R. Hill, and G. Turrell. 1994. Homicidal Somnambulism: A Case Report. Sleep 17 (3): 253-264.

7. Ebrahim, Irshaad Osman, and Peter Fenwick. 2008. Sleeprelated automatism and the law. Medicine, Science, and the Law 48 (2): 124-136.

8. Morrison, Ian, John M.M. Rumbold, and Renata L. Riha. 2014. Medicolegal aspects of complex behaviours arising from the sleep period: a review and guide for the Practising 
sleep physician. Sleep Medicine Reviews 18 (3): 229-240. doi:10.1016/j.smrv.2013.07.004.

9. Wigley, Simon. 2007. Automaticity, consciousness and moral responsibility. Philosophical Psychology 20 (2): 209-225. doi:10.1080/09515080701197122.

10. Di Nucci, E. 2011. Automatic Actions: Challenging Causalism. Rationality Markets and Morals 2 (1): 179-200.

11. Di Nucci, E. 2013. Mindlessness. Newcastle-upon-Tyne: Cambridge Scholars.

12. Di Nucci, E. 2017. Habits, Priming and the Explanation of Mindless Action. Minds and Machines. doi:10.1007 /s11023-016-9410-5.

13. Beilock, Sian L., Bennett I. Bertenthal, Annette M. McCoy, and Thomas H. Carr. 2004. Haste does not always make waste: expertise, direction of attention, and speed versus accuracy in performing sensorimotor skills. Psychonomic Bulletin \& Review 11 (2): 373-379.

14. Beilock, Sian L., Thomas H. Carr, Clare MacMahon, and Janet L. Starkes. 2002. When paying attention becomes counterproductive: impact of divided versus skill-focused attention on novice and experienced performance of sensorimotor skills. Journal of Experimental Psychology. Applied 8 (1): 6-16.

15. Levy, Neil. 2014. Consciousness and moral responsibility. Oxford: Oxford University Press.

16. Levy, Neil, and Tim Bayne. 2004. Doing without deliberation: automatism, automaticity, and moral accountability. International Review of Psychiatry (Abingdon, England) 16 (3): 209-215. doi:10.1080/09540260400003909.

17. Davidson, Donald. 1980. Essays on actions and events. New York: Clarendon Press.

18. Cartwright, Rosalind. 2004. Sleepwalking violence: a sleep disorder, a legal dilemma, and a psychological challenge. American Journal of Psychiatry 161 (7): 1149-1158. doi:10.1176/appi.ajp.161.7.1149.

19. Williams, Bernard. 1990. Voluntary acts and responsible agents. Oxford Journal of Legal Studies 10 (1): 1-10. doi:10.1093/ojls/10.1.1.
20. Williams, Bernard. 1994. The actus Reus of Dr. Caligari. University of Pennsylvania Law Review 142 (5): 16611673. doi:10.2307/3312465.

21. Fischer, J.M., and M. Ravizza. 2000. Responsibility and control: a theory of moral responsibility. Cambridge: Cambridge University Press.

22. Frankfurt, Harry G. 1988. The importance of what We care about: philosophical essays. New York: Cambridge University Press.

23. McKenna, Michael. 2012. Conversation \& responsibility. USA: Oxford University Press.

24. Scanlon, Thomas. 2008. Moral dimensions: permissibility, meaning, blame. Cambridge: Harvard University Press.

25. Williams, Bernard. 2008. Shame and necessity. Berkeley: University of California Press.

26. Kenny, Anthony. 1992. The Metaphysics of Mind. Oxford University Press. http://www.oxfordscholarship. com/view/10.1093/acprof:oso/9780192830708.001.0001 /acprof-9780192830708.

27. Saks, Elyn R., and Stephen H. Behnke. 2000. Jekyll on trial: multiple personality disorder and criminal law. New York: NYU Press.

28. Watson, G. 1987. Responsibility and the limits of evil: variations on a Strawsonian theme. In Responsibility, character and the emotions: new essays in moral psychology, ed. F. Shoeman, 256-286. Cambridge: Cambridge University Press.

29. Duff, R. A. 1991. Trials and punishments. CUP Archive.

30. Gardner, John. 2007. Offences and Defences: selected essays in the philosophy of criminal law. Oxford: Oxford University Press.

31. Sher, G. 2009. Who knew? Responsibility without awareness. Oxford: Oxford University Press.

32. Tognazzini, Neal A. 2010. Review of George Sher's Who Knew? Responsibility Without Awareness. Notre Dame Philosophical Reviews. http://ndpr.nd.edu/review. cfm?id=18430.

33. Williams, Bernard. 1993. Moral Luck. Cambridge: Cambridge University Press. 